\title{
Identification and Mitigation of Generated Solid Byproducts during Advanced Electrode Materials Processing
}

Candace S.J.Tsai ${ }^{1,2 *}$, Arthur D. Dysart ${ }^{3}$, Jay H. Beltz ${ }^{4}$, Vilas G. Pol ${ }^{3 *}$

${ }^{1}$ Department of Environmental and Radiological Health Sciences, College of Veterinary

Medicine and Biomedical Sciences, Colorado State University, 80528, CO

${ }^{2}$ Birck Nanotechnology Center, Discovery Park, Purdue University, 47907, IN

${ }^{3}$ School of Chemical Engineering, College of Engineering, Purdue University, 47907, IN

${ }^{4}$ School of Health Science, College of Health and Human Science, Purdue University, 47907, IN

Corresponding author 1 :

* Prof. Candace S.J. Tsai

Department of Environmental and Radiological Health Sciences, College of Veterinary Medicine and Biomedical Sciences, Colorado State University

Address: 1681 Campus Delivery, Fort Collins, CO 80523-1681

Email: Candace.Tsai@,colostate.edu

$\mathrm{P}+1(970)$ 491-1340

$\mathrm{F}+1(970)$ 491-2940

Corresponding author 2:

* Prof. Vilas G. Pol

School of Chemical Engineering, Forney Hall of Chemical Engineering, Purdue University Address: 480 Stadium Mall Drive, West Lafayette, IN 47907-2100

Email: vpol@purdue.edu

$\mathrm{P}+1(765)$ 494-0044

$\mathrm{F}+1(765)$ 494-0805 


\section{SUPPORTING INFORMATION}

\section{Table of Contents}

Furnace setup

Figure SI1: Thermogravimetric analysis (TGA) of the starch precursor to determine the temperatures at which mass loss is observed

Figure SI2: (a) Starch-based precursor, (b) Carbon Micro-Hotels. This SEM micrograph shows the presence of many micrometer-sized carbon particles.

Figure. SI3a. Temperature profile and mass concentration of exhaust gas S3 Figure SI3b. Particle size (median, mean and mode) profiles of emitted particles in the range

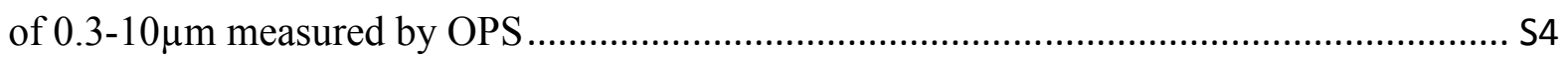

Figure SI4. Particle size distribution of exhaust gas over a size range of $0.3-10 \mu \mathrm{m} . . . \ldots \ldots \ldots . . . .55$

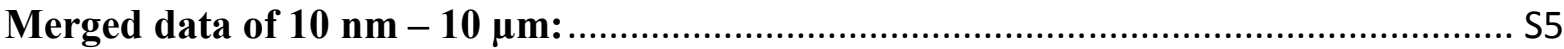

Figure SI5. Merged composite particle size distribution for a size range of $10 \mathrm{~nm}$ to $10 \mu \mathrm{m} . \mathrm{S} 6$ Figure SI6. Particle size distribution in liquid suspension collecting exhausted particles. .... S7 Figure SI7. Particles penetrating the water bath collected on a TEM grid. (a) and (b) overview of accumulated particle agglomerates on grid and EDX data, (c) and (d) a large agglomerate image and EDX data of spot scan 


\section{Furnace setup}

The components used to evaluate this furnace and the connections to the furnace are illustrated in

Fig. 1. A dilution chamber was used in line with the exhaust from the furnace to dilute aerosol concentrations to be within the maximum detectable range of direct-reading instruments. This chamber is an acrylic plastic cube with hose barbs connected on two opposite ends; a North Safety Highly Toxic HEPA filter (7500-8) was installed on the top as inlet air for dilution. The filter chamber was sealed and replacement air was drawn through the chamber's filter when needed. This filter also served as a pressure release should pressure build up in the system.

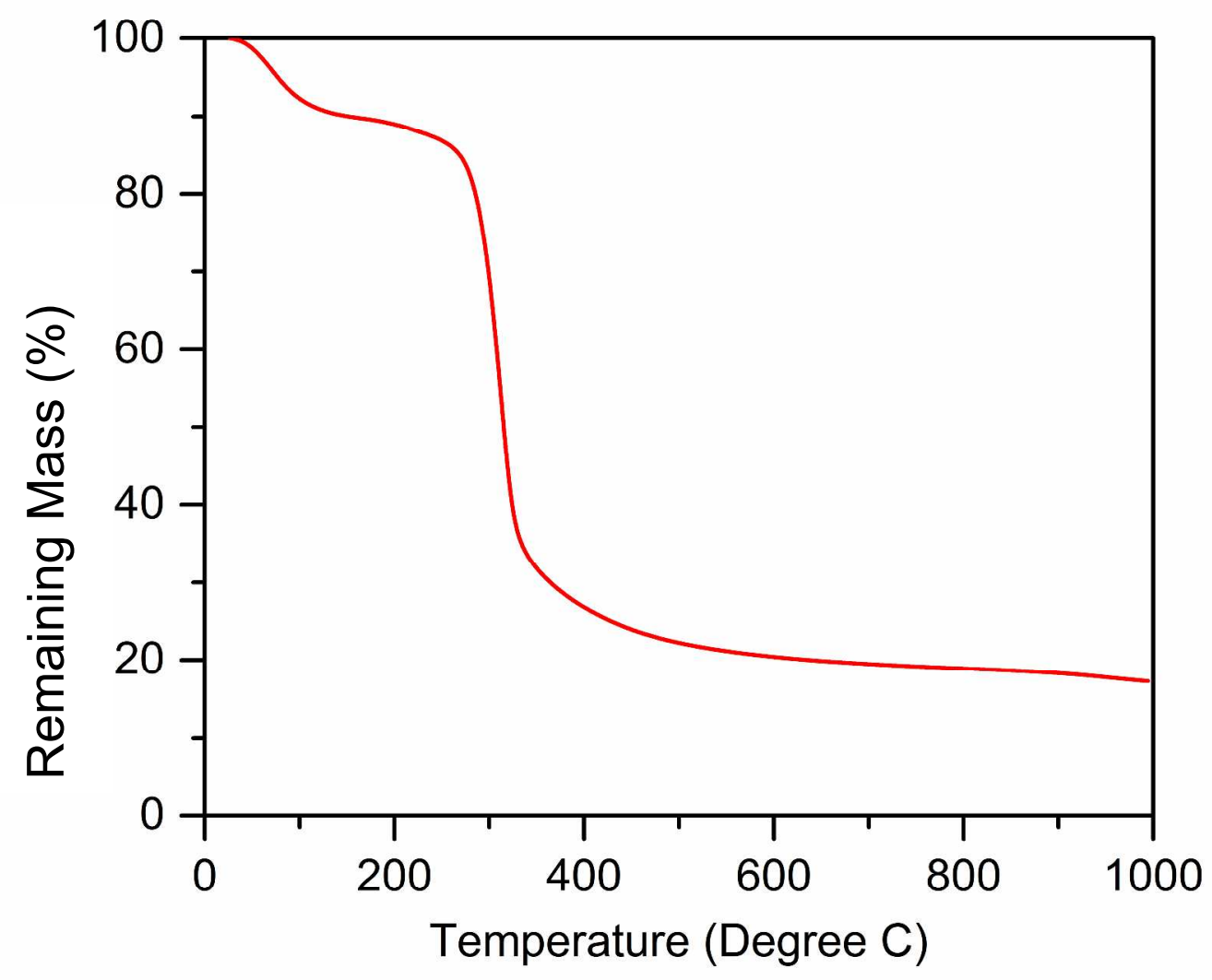

Figure SI1: Thermogravimetric analysis (TGA) of the starch precursor to determine the temperatures at which mass loss is observed. 

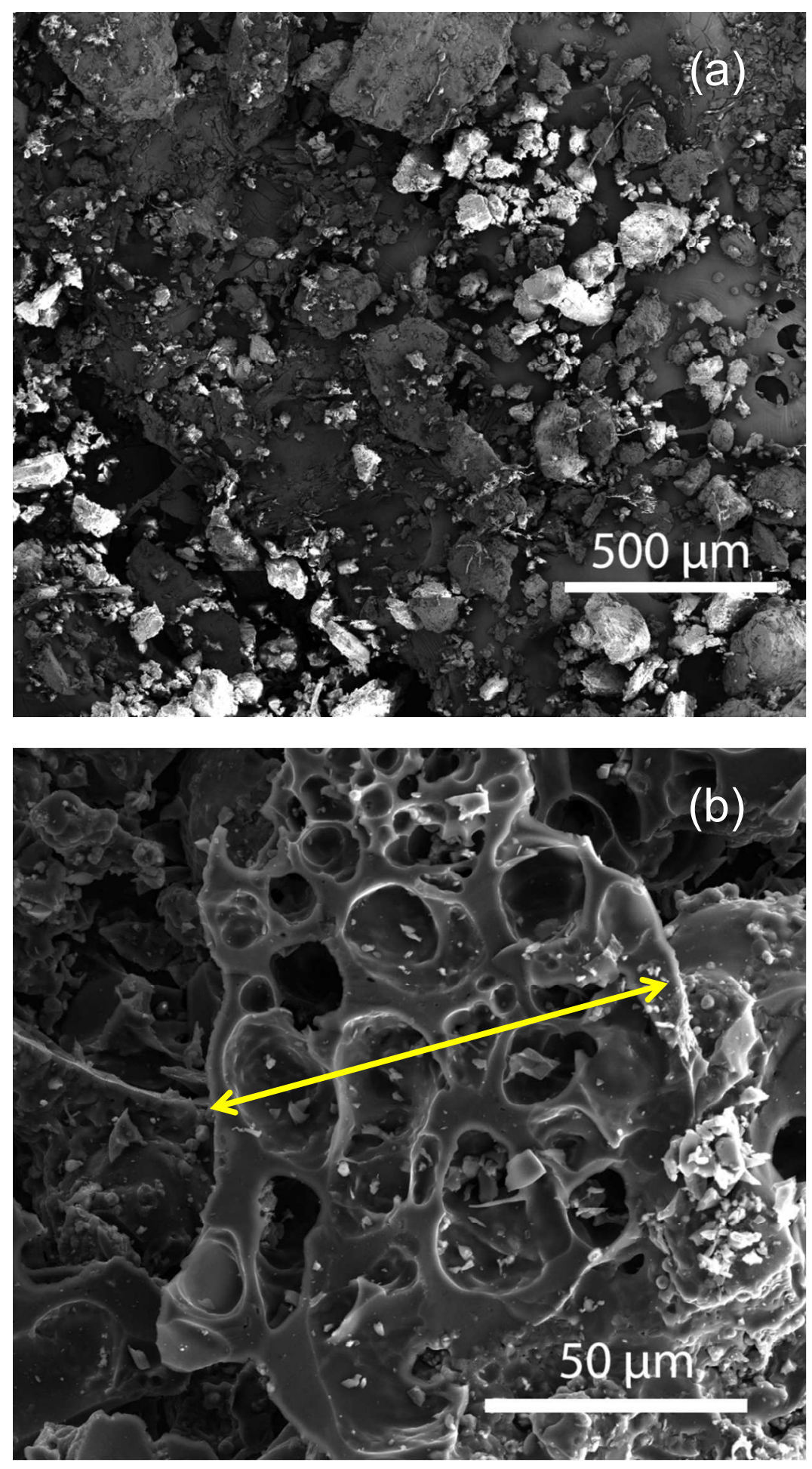

Figure SI2: (a) Starch-based precursor, (b) Carbon Micro-Hotels. This SEM micrograph shows the presence of many micrometer-sized carbon particles. 


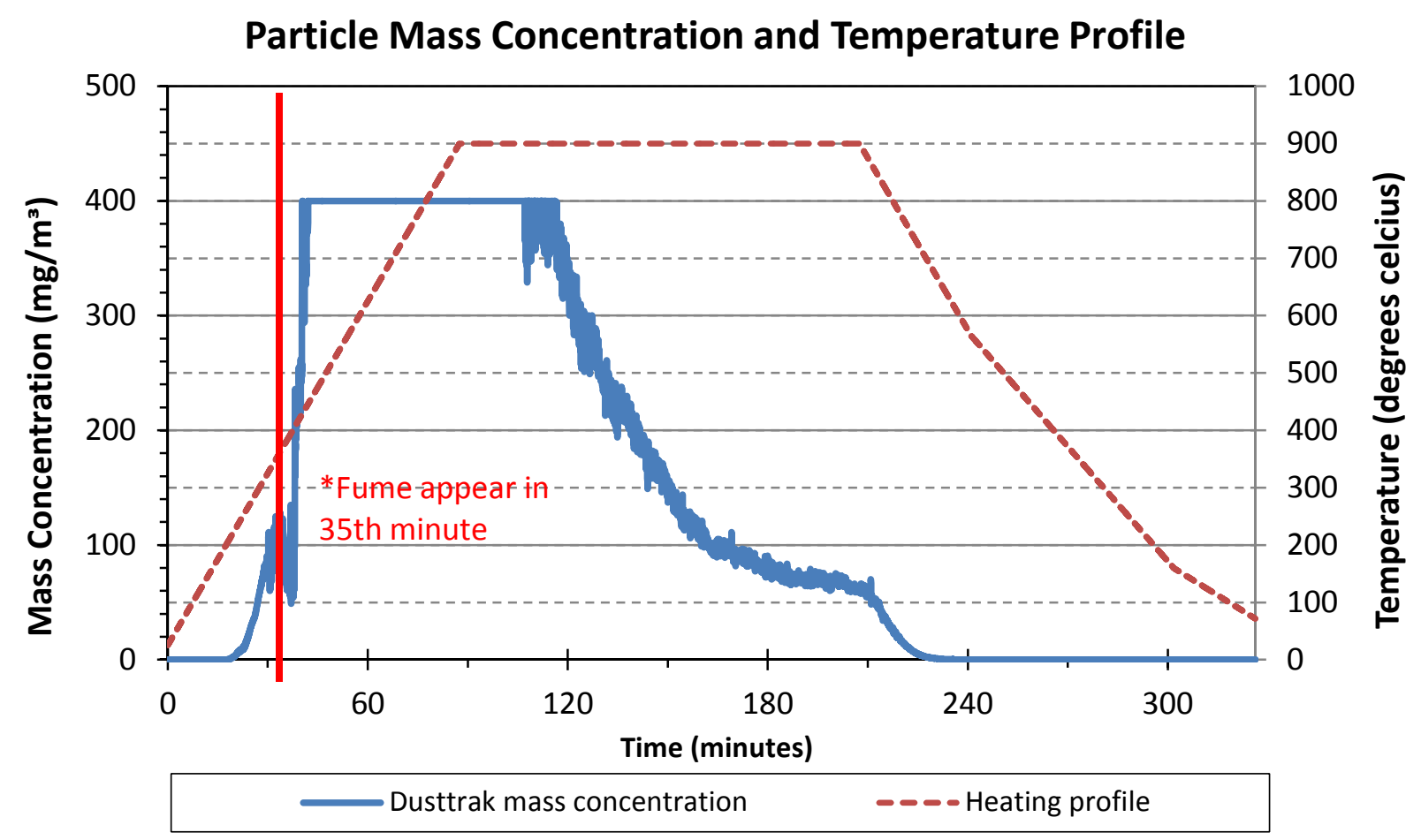

Figure. SI3a. Temperature profile and mass concentration of exhaust gas 


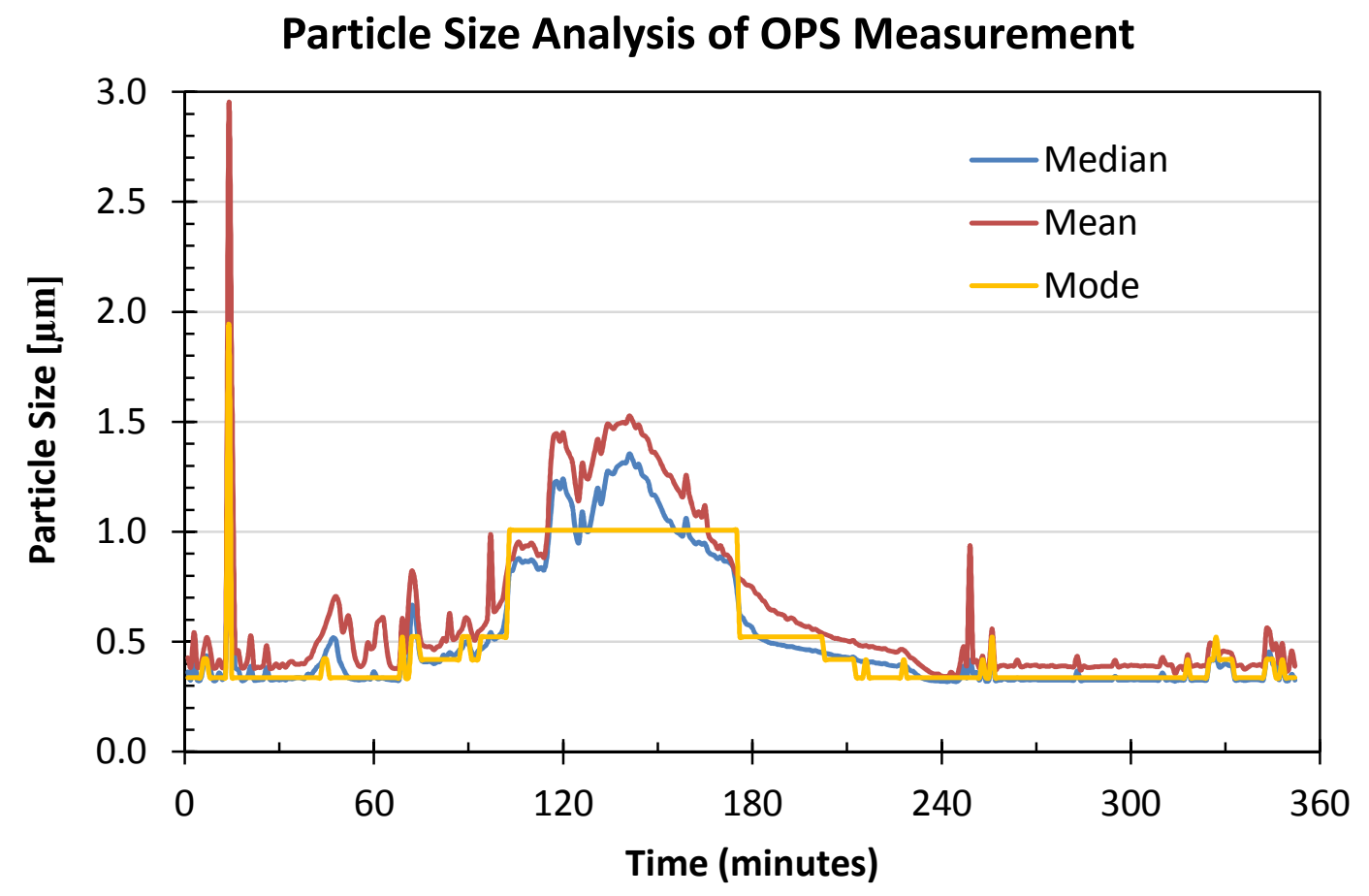

Figure SI3b. Particle size (median, mean and mode) profiles of emitted particles in the range of $0.3-10 \mu \mathrm{m}$ measured by OPS 


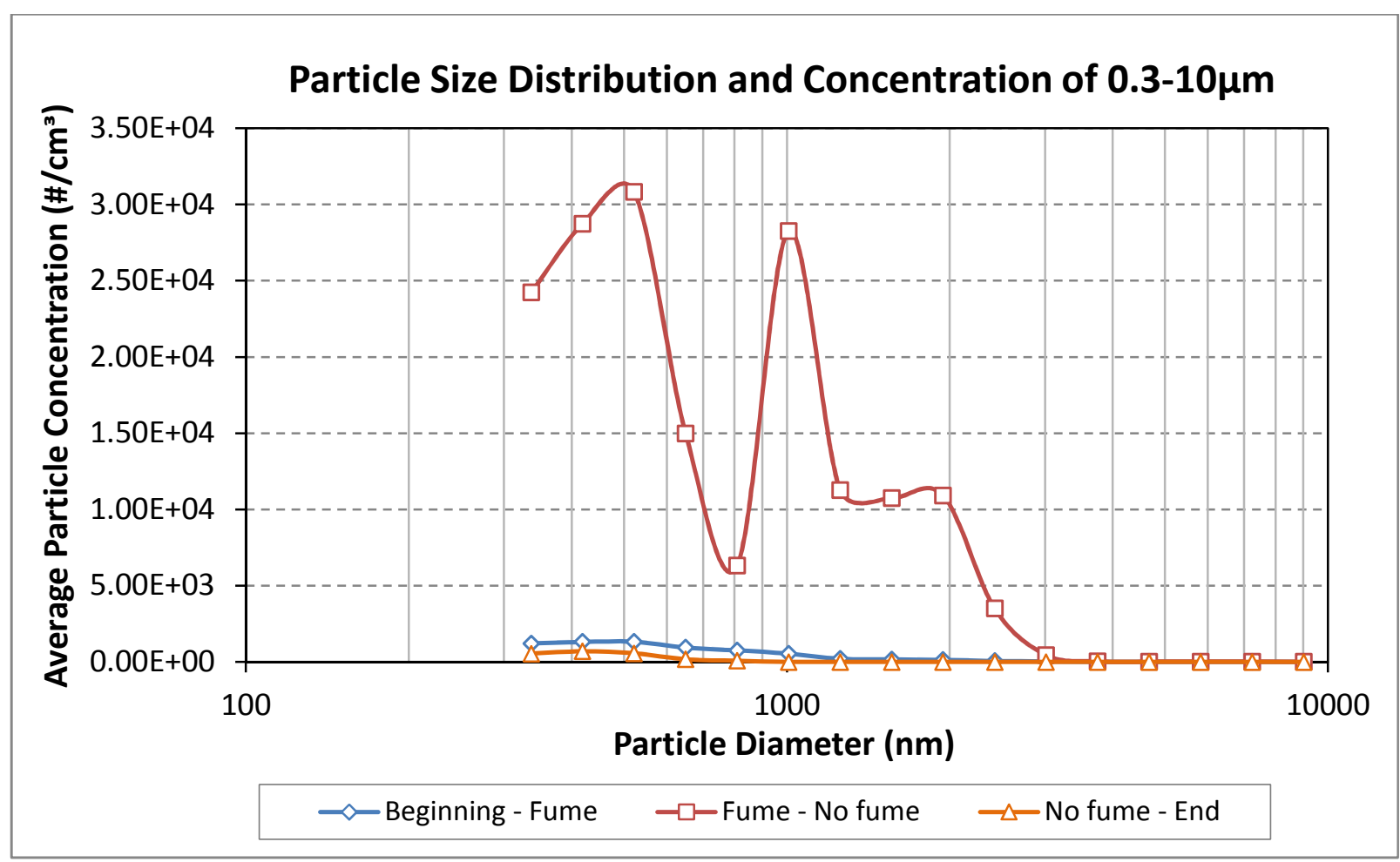

Figure SI4. Particle size distribution of exhaust gas over a size range of 0.3-10 $\mu \mathrm{m}$.

\section{Merged data of $10 \mathrm{~nm}-10 \mu \mathrm{m}$ :}

Composite graphs that combine the NanoScan and OPS total concentration vs. particle size data were created using graphing software. Fig. SI4 shows the first composite graph representing the particle size profile at the maximum concentration measured by the NanoScan and OPS. The maximum concentration measured by both the NanoScan and OPS occurred at 200 min towards the end of the two hour hold time at $900{ }^{\circ} \mathrm{C}$. The other composite profile shown in Fig SI4 displays the average particle concentration during the entire furnace run for each particle size range. Both composite data profiles show a similar trend of the highest concentration of particles emitted being between 200-300 $\mathrm{nm}$. The composite graph at $200 \mathrm{~min}$ has the highest measured particle concentration of $\sim 1.8 \times 10^{6}$ particles $/ \mathrm{cm}^{3}$ and also shows a small peak at $35 \mathrm{~nm}$ with a 
concentration of $1.5 \times 10^{6}$ particles $/ \mathrm{cm}^{3}$. The average composite profile shows the maximum average concentration is $\sim 3.6 \times 10^{5}$ particles $/ \mathrm{cm}^{3}$.

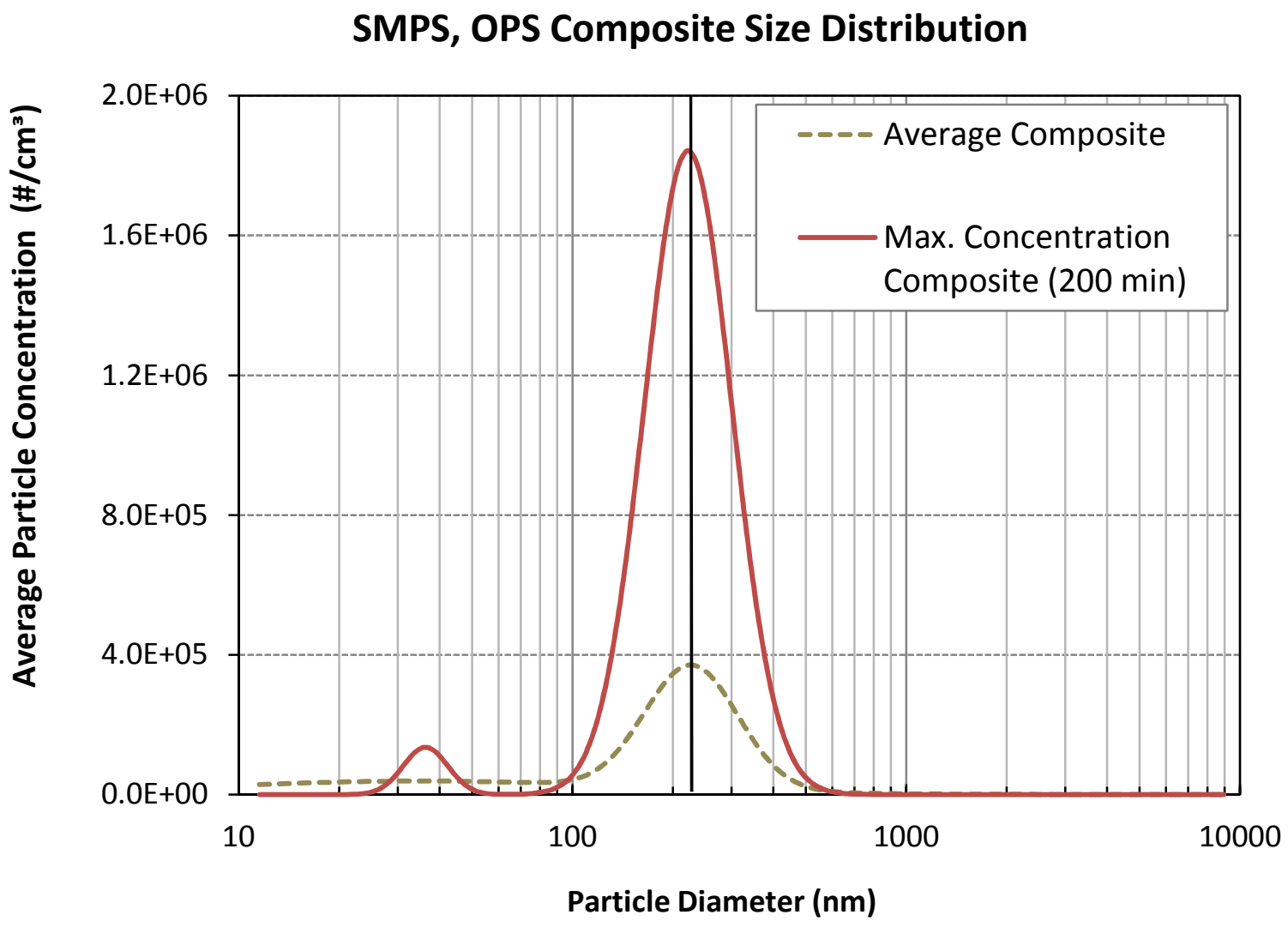

Figure SI5. Merged composite particle size distribution for a size range of $10 \mathrm{~nm}$ to $10 \mu \mathrm{m}$. 


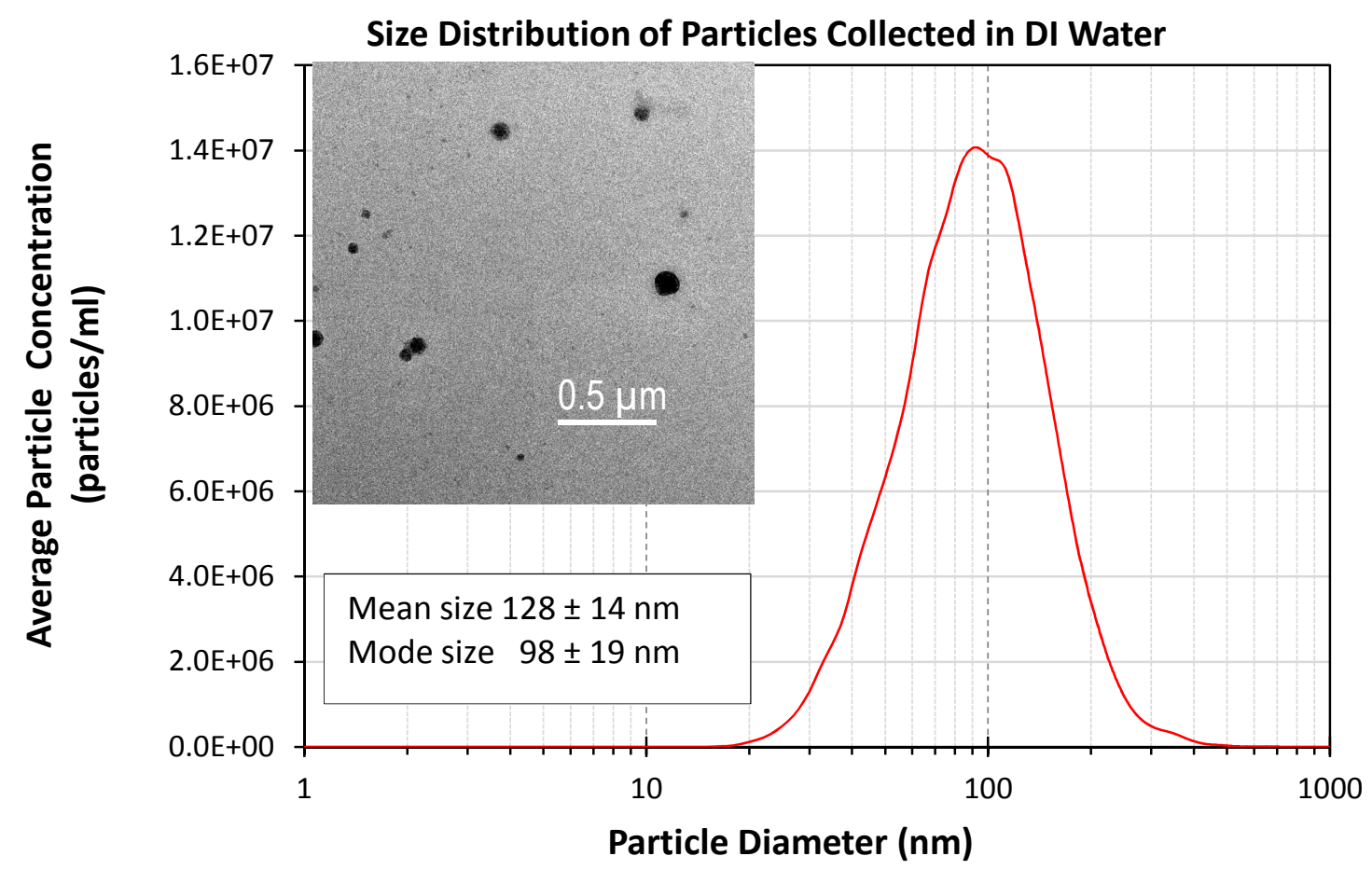

Figure SI6. Particle size distribution in liquid suspension collecting exhausted particles. 


\section{Electron Image 1}
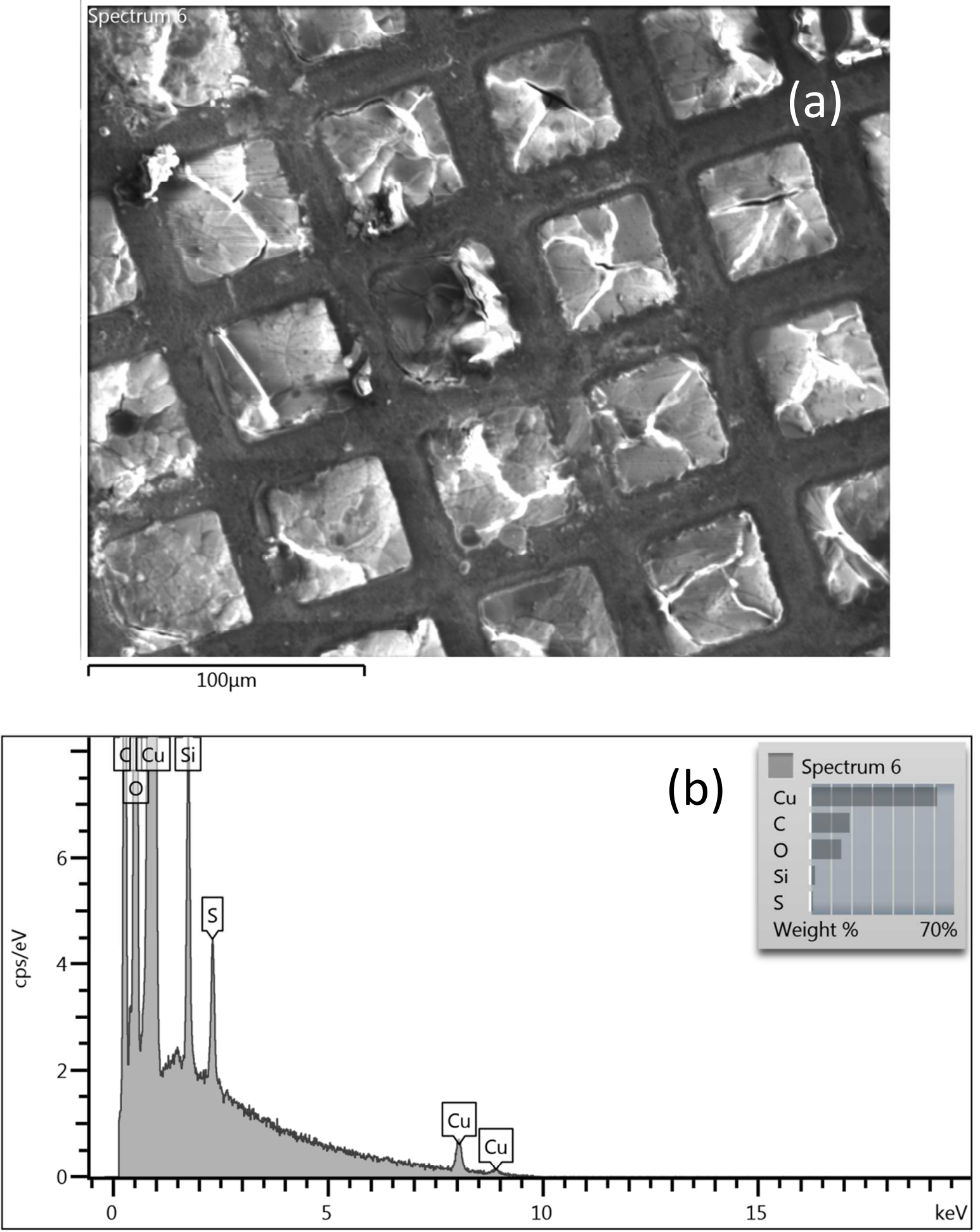
Electron Image 3
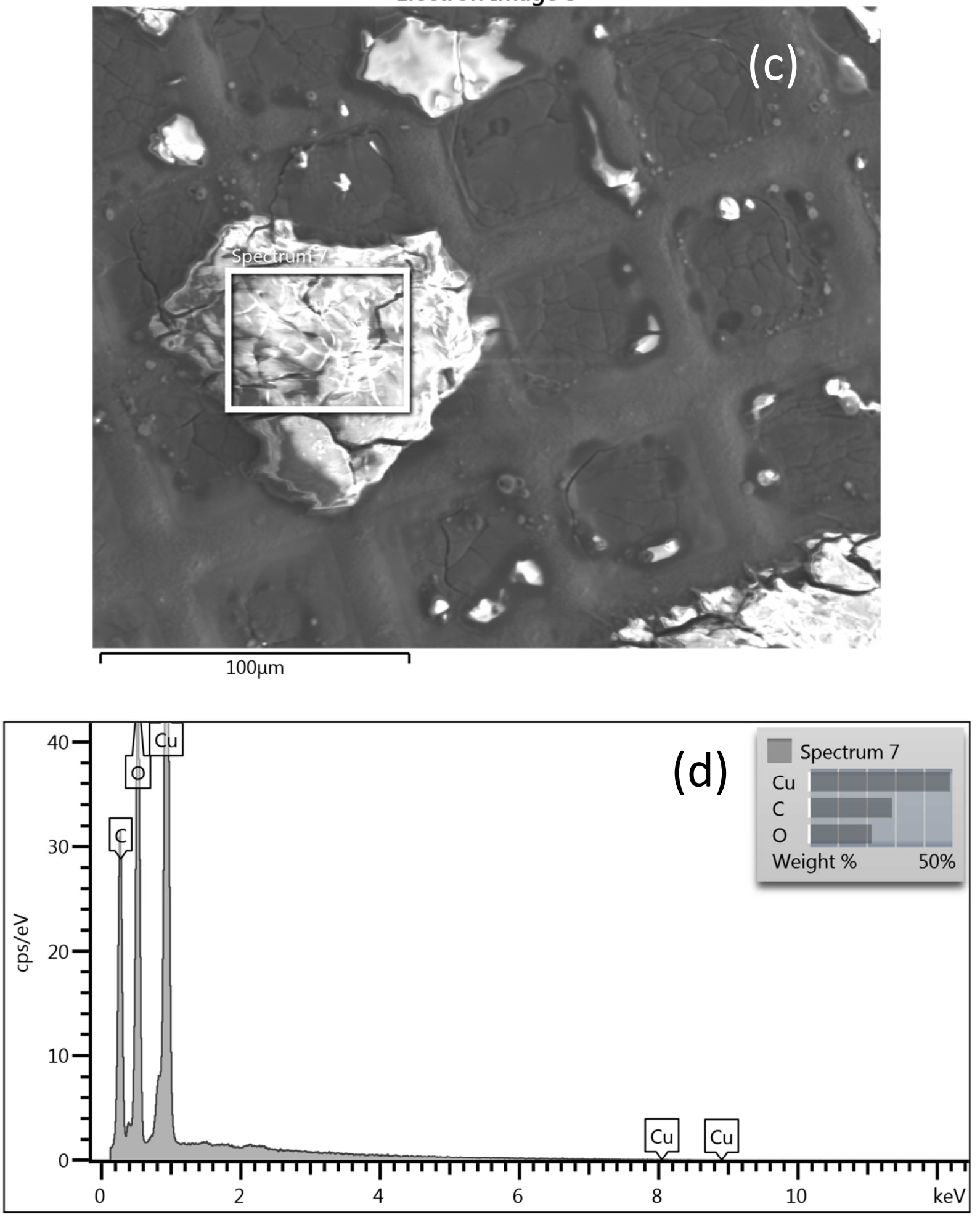
Figure SI7. Particles penetrating the water bath collected on a TEM grid. (a) and (b) overview of accumulated particle agglomerates on grid and EDX data, (c) and (d) a large agglomerate image and EDX data of spot scan. 